\title{
The Effects of Sodium Nitroprusside on Blood Flow and Oxygen Delivery to the Organs of the Hypoxemic Newborn Lamb
}

\author{
ROBERT MIRRO, J. ROSS MILLEY, AND IAN R. HOLZMAN \\ Department of Pediatrics, Division of Neonatology, University of Pittsburgh School of Medicine, Magee-Womens \\ Hospital, Pittsburgh, Pennsylvania
}

\begin{abstract}
Vasodilators are used in newborns under conditions where hypoxia may be prominent. To study the effects of vasodilator therapy on organ oxygen delivery we measured blood flow (using radioactive microspheres) and arterial oxygen content in six chronically catheterized newborn lambs. Cardiac output and its distribution were measured during normoxia, hypoxia $\left(10 \% \mathrm{O}_{2}\right.$ and $\left.5 \% \mathrm{CO}_{2}\right)$, and hypoxia with a nitroprusside infusion. Hypoxia decreased oxygen content but did not change heart rate, mean blood pressure, or cardiac output. When nitroprusside was infused during hypoxemia, oxygen content and heart rate were not affected, but mean arterial blood pressure fell (39\% decrease). During hypoxemia, blood flow increased to the heart, brain, and carcass but decreased to the gastrointestinal tract. When nitroprusside was infused during hypoxemia, blood flow decreased to the heart, brain, kidneys, and carcass. Oxygen delivery. (arterial $\mathrm{O}_{2}$ content $x$ blood flow) decreased to the brain as well as to kidneys, stomach, and carcass when nitroprusside was given to the hýpoxemic lamb. (Pediatr Res 19: 15-18, 1985)
\end{abstract}

Hypoxemia often accompanies neonatal cardiopulmonary disease. Such common problems as hyaline membrane disease, pneumonia, aspiration syndromes, cyanotic congenital heart disease, and persistent fetal circulation may present with hypoxemia as a prominent finding $(8,14,20)$. When conventional therapy (high inspired oxygen concentration and mechanical ventilation) fails to increase arterial $\mathrm{PO}_{2}$, pharmacologic agents have been used. In general, drug therapy is aimed at increasing arterial oxygen content by increasing pulmonary blood flow and thus is employed primarily when pulmonary blood flow is thought to be reduced as a result of pulmonary arterial vasoconstriction.

Sodium nitroprusside is a potent, direct-acting vasodilator which has been used for systemic hypertension (16), pulmonary hypertension (7), and congestive heart failure $(6,17)$. Although experience with nitroprusside in the neonate is limited, two case reports $(1,4)$ have suggested that nitroprusside may have a therapeutic role in decreasing the high pulmonary vascular resistance of hyaline membrane disease.

Nitroprusside is an iron-coordinated complex surrounded by cyanide groups with a single nitroso group (16). The drug is metabolized in the liver to cyanide which is then quickly con-

Received October 20, 1983; accepted July 11, 1984.

Correspondence J. Ross Milley, M.D., Ph.D., Department of Pediatrics, Division of Neonatology, Magee-Womens Hospital, Forbes Avenue and Halket Street, Pittsburgh, PA 15213 .

This research was supported by a Grant-in-Aid from the Western Pennsylvania Heart Association, Inc. verted to thiocyanate. Cyanide and thiocyanate may have toxic effects which result in tissue hypoxia and resultant metabolic acidosis. Thiocyanate levels of $10-20 \mathrm{mg} / 100 \mathrm{ml}(16)$ result in adverse clinical symptoms. As toxic products accumulate during infusion, hazard increases when the infusion is prolonged.

Further information about the response of the newborn's systemic circulation to vasodilator therapy, especially under hypoxemic conditions, would help to show when their use is appropriate. The purpose of this experiment is to examine the effect of nitroprusside on the distribution of tissue blood flow and oxygen delivery during hypoxemia.

\section{MATERIALS AND METHODS}

Animals. We operated on six lambs, 3-4 days of age, using ketamine (Ketalar, Parke-Davis) $(10 \mathrm{mg} / \mathrm{kg}$ im), and local $(1 \%$ xylocaine) anesthesia. In each animal, polyvinyl catheters (i.d. $0.76 \mathrm{~mm}$; o.d. $1.22 \mathrm{~mm}$ ) were placed into both hind limb arteries and advanced to the descending aorta. We also placed a catheter in one hind limb vein and advanced it to the inferior vena cava. Through a neck incision, a catheter was placed in the left ventricle via the carotid artery. All catheters were filled with heparin (1000 unit $/ \mathrm{ml}$ ) and were brought subcutaneously to the lamb's back where they were stored in a gauze pouch. The lambs were allowed to recover until fully awake and then returned to their pens where they were free to feed. Two to three days after surgery, at a time when intracardiac and ductal shunts are no longer detectable (19), the lambs were brought back to the laboratory and placed in a plexiglass box where they were allowed to adapt to these surroundings prior to study. The animals were unanesthetized and unrestrained. The laboratory is maintained at an ambient temperature between $21-22^{\circ} \mathrm{C}$

Experimental protocol. One hind limb arterial catheter was connected to a Statham P23Db pressure transducer to measure blood pressure. Heart rate was obtained from a cardiotachometer coupled to the blood pressure channel. Both measurements were recorded continuously on a Beckman R611 direct writing recorder. Control hematocrit, $\mathrm{pH}$, and arterial blood gas samples were obtained from a hind limb arterial catheter $(0.5 \mathrm{ml})$. Hematocrit was measured by the microhematocrit method. Blood gas samples were measured using a Corning blood gas meter (Corning Instruments, Corning, NY). In addition, arterial oxygen content samples $(0.2 \mathrm{ml})$ were obtained anaerobically and immediately analyzed on a Lex- $\mathrm{O}_{2}$-Con (Lexington Instruments, Waltham, MA) oxygen analyzer. Serum samples $(1 \mathrm{ml})$ were obtained for cyanide [quantitative assay using the Conway microdiffusion method (10)] and thiocyanate [spectrophotometric method of Aldridge (2)]. Immediately after these samples were obtained, approximately $1 \times 10^{6}$ microspheres $(15 \mu \mathrm{m}$ diameter $)$ labeled with $125-\mathrm{I}, 85-\mathrm{SR}$, or $46-\mathrm{SC}$ were injected into the left 
ventricular catheter over $20 \mathrm{~s}$ (18). A blood reference sample was withdrawn from the remaining hind limb arterial catheter using a withdrawal pump (rate $=3.8 \mathrm{ml} / \mathrm{min}$ ), beginning before the microsphere injection and ending $60 \mathrm{~s}$ after the injection catheter was flushed with saline (15). The animal was then made hypoxemic by introducing a gas mixture of $9-10 \% \mathrm{O}_{2}$ and $5 \% \mathrm{CO}_{2}$ (to maintain constant arterial $\mathrm{PCO}_{2}$ ) into the plexiglass box. The inflowing gas was cooled in order to maintain the temperature within the plexiglass box at ambient room temperature. After a period of equilibration ( $30 \mathrm{~min}$ ), samples were again obtained for all studies outlined above (except cyanide and thiocyanate) and a second microsphere injection (using an alternately labeled isotope) and reference withdrawal were done. Sampling and microsphere injections were accomplished within $5 \mathrm{~min}$. Finally, an infusion of sodium nitroprusside was begun at $20 \mu \mathrm{g} / \mathrm{kg} / \mathrm{min}$ (the dose needed to decrease mean arterial blood pressure by approximately one-third) through the hind limb venous catheter. When the arterial blood pressure had equilibrated $(30 \mathrm{~min})$ samples for $\mathrm{pH}$, arterial blood gases, $\mathrm{O}_{2}$ content, cyanide, and thiocyanate were obtained and a third microsphere injection (with an isotope labeled differently from the first two) and reference withdrawal were performed. Reference artery blood samples contained more than 2700 microspheres to ensure a blood flow measurement error of less than $5 \%$ at the $99 \%$ confidence limits (5). In a preliminary investigation (utilizing both an upper and lower body withdrawal) we confirmed, for the purpose of this study, that brain blood flow was accurately measured with a descending aorta reference catheter.

Preparation of tissues and analysis of data. At the end of the study the lambs were killed with a narcotic overdose. All catheter locations were visually identified at autopsy and the gastrointestinal contents removed. All organs were weighed and incinerated at $280^{\circ} \mathrm{C}$ for $72 \mathrm{~h}$ after which the ash was packed in counting vials. The amounts of each radionuclide in the organs and the reference arterial.blood samples were measured with a well-type $\gamma$ scintillation counter (Model 1185R, Searle Analytical) with a 1024-channel pulse-height analyzer (Ultima II, Norland). Nuclide isotope separation was performed by a computer (Nova 3 , Data General) using a previously verified (3) program.

Organ blood flow $\left(\dot{\mathrm{Q}}_{\mathrm{org}}\right)$ was computed as follows:

$$
\dot{\mathrm{Q}}_{\text {org }}=\left(\mathrm{cpm}_{\text {org }} / \mathrm{cpm}_{\mathrm{ref}}\right) \times\left(\dot{\mathrm{Q}}_{\mathrm{ref}}\right)
$$

where $\mathrm{cpm}_{\text {org }}$ is the radioactive $\mathrm{cpm}$ in the organ, $\mathrm{cpm}_{\text {ref }}$ is the radioactive cpm in the reference arterial blood sample, $\mathrm{Q}_{\mathrm{ref}}$ is the reference arterial blood flow determined by calibrating the withdrawal pump. Cardiac output is the sum of all organ and carcass flows. Flows were calculated by dividing the organ flow $(\mathrm{ml} / \mathrm{min})$ by the weight (in $100 \mathrm{~g}$ ). Oxygen delivery is the product of flow and $\mathrm{O}_{2}$ content expressed in the units $\mathrm{ml} \mathrm{O} / \mathrm{min} / 100 \mathrm{~g}$. Left and right brain hemispheres and left and right kidneys were evaluated separately to establish adequate microsphere mixing in the arterial circulation $(5,11)$.

The data were analyzed by comparing each organ flow (ml/ $\min / 100 \mathrm{~g}$ tissue) at three time periods (baseline; hypoxia; hypoxia plus nitroprusside) using a two-factor analysis of variance without replication. If a given variable was not the same through all of the treatments, the Newman-Keuls test was used to distinguish which time period (treatment) was different from the others (24). The same analysis was applied to the oxygen delivery data. All data are reported as means \pm SEM.

\section{RESULTS}

Hematocrits of the animals ranged from $28-36 \%$ at the start of the experiment and did not significantly decrease over the course of the study. Body weights ranged from 3.5 to $7.6 \mathrm{~kg}$ with a mean of $5.1 \mathrm{~kg}$ at the time of experimentation.

Data listed in Table 1 show that heart rate was not affected by the experimental conditions, while mean arterial pressure was significantly changed by nitroprusside infusion but not by hypoxemia. As expected, the lambs showed a significant decrease in both arterial oxygen content and oxygen tension while the inspired oxygen concentration was lowered. $\mathrm{pH}$ and $\mathrm{PCO}_{2}$ were not affected by the experimental conditions imposed.

Cardiac output was $326 \pm 37 \mathrm{ml} / \mathrm{min} / \mathrm{kg}$ before hypoxemia and $392 \pm 59 \mathrm{ml} / \mathrm{min} / \mathrm{kg}$ during hypoxemia, a change that was not significant. Five of the six lambs did, however, demonstrate a higher cardiac output during hypoxemia. With the addition of sodium nitroprusside, cardiac output fell to $304 \pm 58 \mathrm{ml} / \mathrm{min} /$ $\mathrm{kg}$, a decrease of $22 \%$ when compared to cardiac output during hypoxemia. This decrease was not significant by analysis of variance although cardiac output did decrease in each animal.

Changes in organ blood flow during this experiment are shown in Figure 1. During hypoxemia blood flow to the heart, brain, and carcass increased, while blood flow to the stomach decreased. Blood flow to the small intestine and kidneys did not change significantly. During nitroprusside infusion, kidney and carcass blood flows decreased when compared to those same flows obtained during hypoxemia alone.

Hypoxemia caused decreased oxygen delivery to the kidneys, small intestine, and stomach (Fig. 2). In the remaining organs, oxygen delivery was not changed by hypoxemia. Infusion of nitroprusside during hypoxemia significantly decreased oxygen delivery to the brain, kidney, and carcass (Fig. 2).

During these experiments, there was no detectable cyanide present in whole blood, and thiocyanate concentrations were less than $1 \mathrm{mg} / 100 \mathrm{ml}$.

\section{DISCUSSION}

Acute hypoxemia in both newborn and adult animals has been consistently associated with circulatory changes so that oxygen delivery to the most metabolically active organs (such as heart and brain) is maintained. Increased cardiac output has been reported in the hypoxemic newborn lamb (13) and accounts, in

Table 1. Physiologic data during experimental conditions

\begin{tabular}{|c|c|c|c|}
\hline \multirow[b]{2}{*}{ Variable } & \multicolumn{3}{|c|}{ Experimental condition } \\
\hline & $\begin{array}{c}\text { Breathing room air } \\
\text { no infusion }\end{array}$ & $\begin{array}{c}\text { Breathing } 9-10 \% \text { oxygen } \\
\text { no infusion }\end{array}$ & $\begin{array}{c}\text { Breathing } 9-10 \% \text { oxygen } \\
\text { nitroprusside infusion }\end{array}$ \\
\hline Mean arterial pressure (Torr) & $64 \pm 4^{*}$ & $64 \pm 4$ & $38.5 \dagger$ \\
\hline Heart rate $(\mathrm{bpm})$ & $184 \pm 16$ & $206 \pm 25$ & $152 \pm 15$ \\
\hline Cardiac output $\left(\mathrm{ml} \cdot \mathrm{kg}\right.$ body $\left.\mathrm{wt}^{-1}\right)$ & $326 \pm 37$ & $392 \pm 59$ & $304 \pm 58$ \\
\hline Arterial oxygen content $\left(\mathrm{mmol} \cdot\right.$ liter blood $\left.^{-1}\right)$ & $5.39 \pm 0.19$ & $3.47 \pm 0.32 \ddagger$ & $3.02 \pm 0.42 \dagger$ \\
\hline $\mathrm{pH}$-arterial & $7.49 \pm 0.01$ & $7.48 \pm 0.02$ & $7.42 \pm 0.04$ \\
\hline $\mathrm{PO}_{2}$-arterial (Torr) & $88 \pm 3$ & $37 \pm 3 \ddagger$ & $38 \pm 4 \ddagger$ \\
\hline $\mathrm{PCO}_{2}$-arterial (Torr) & $33 \pm 1$ & $34 \pm 1$ & $33 \pm 3$ \\
\hline
\end{tabular}

$* \pm$ SEM.

$\dagger=p<0.001$ (compared to hypoxia alone).

$\ddagger=p<0.001$ (compared to room air). 


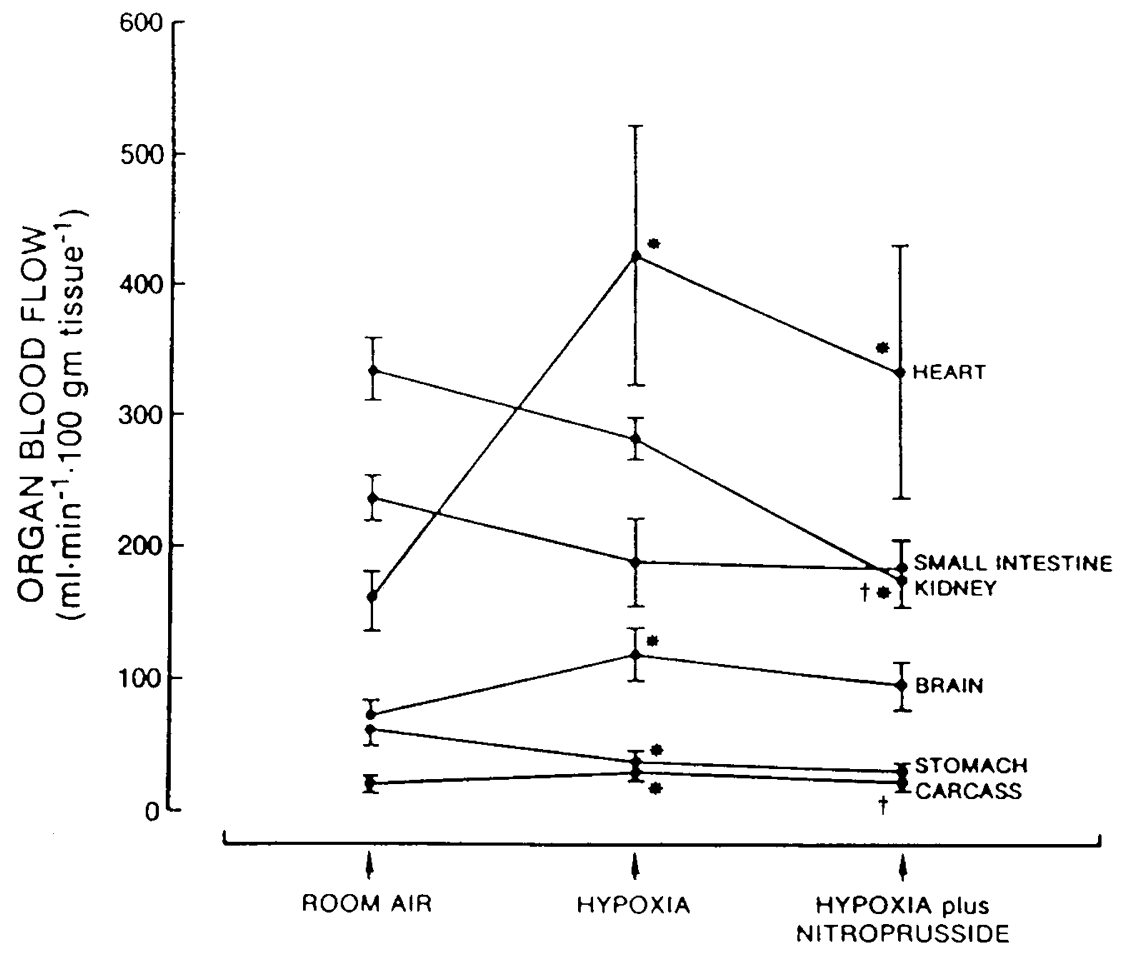

Fig. 1. Changes in organ blood flows during hypoxia and hypoxia plus nitroprusside infusion. *Significantly different than room air value by analysis of covariance, $p<0.05$. †Significantly different than hypoxia value by analysis of covariance, $p<0.05$.

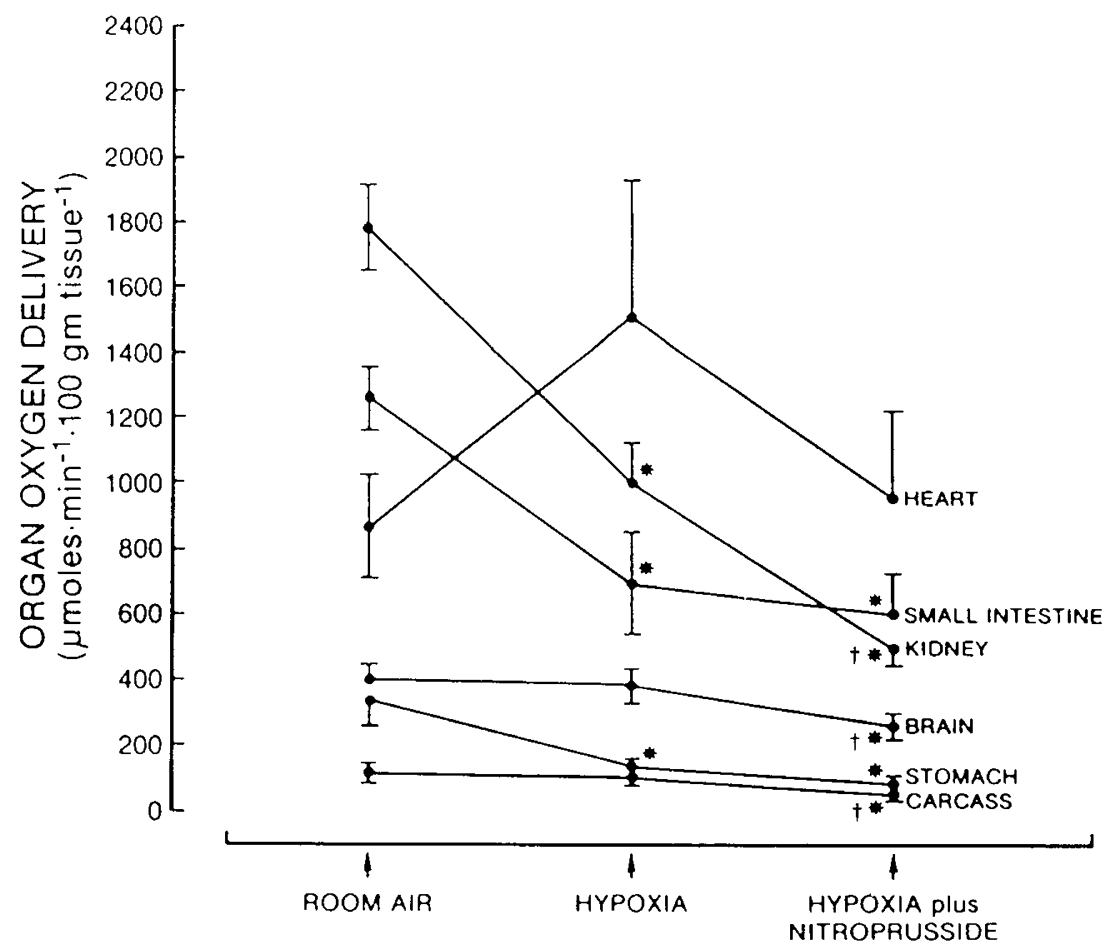

Fig. 2. Change in oxygen delivery during hypoxia and hypoxia plus nitroprusside infusion. *Significantly different than room air value by analysis of covariance, $p<0.05$. † Significantly different than hypoxia value by analysis of covariance, $p<0.05$.

part, for the increased blood flow needed to maintain oxygen delivery to these organs while changes in flow to other organs remain minimal. Although we did not demonstrate a significant increase in cardiac output during hypoxemia, our results remain compatible with previous studies. The changes in cardiac output seen by Sidi et al. (19) were also rather modest in 1-wk-old lambs. They attributed this difference in young lambs to the preexisting higher resting values. During infusion of nitroprusside to the hypoxemic lamb, cardiac output fell in each of the lambs and was accompanied by a significant decrease in blood pressure. Reports from experiments with adult mammals (16) have shown that while nitroprusside is consistent in lowering arterial blood pressure, it causes variable changes in cardiac performance which are probably dependent on the preexisting cardiac performance state.

During arterial hypoxemia in the newborn, heart and brain 
receive an increasing fraction of the cardiac output. As arterial oxygen content falls, an increase in blood flow causes oxygen delivery to the myocardium and brain to remain constant. In the newborn lamb, $40-50 \%$ of the oxygen available to the cerebral circulation is extracted under normal circumstances (12). Since increases in oxygen extraction are limited, adequate oxygen delivery is critical in maintaining normal cerebral oxygen consumption. We find that cerebral blood flow rose during hypoxemia so that oxygen delivery remained constant. When nitroprusside was infused, however, there was a small decrease in cerebral blood flow which led to a significant decrease in cerebral oxygen delivery. Thus, nitroprusside decreased the oxygen delivery to an important organ which has a limited ability to increase oxygen extraction and is, therefore, directly dependent on oxygen delivery for normal metabolic function.

The circulatory adjustments of the neonatal gastrointestinal tract to arterial hypoxemia differ from those described for the brain. As arterial oxygen content decreases, there is a concurrent decrease in gastrointestinal blood flow (9). Oxygen delivery, the product of arterial oxygen content and blood flow, must therefore also decrease. Previous studies have shown that increased oxygen extraction by the neonatal gastrointestinal tract allows for a stable oxygen consumption despite this decreased delivery. When oxygen content reaches a critical minimum, increased oxygen extraction is no longer possible and oxygen consumption falls as oxygen delivery decreases (9). In the present study, hypoxemia decreased oxygen delivery to the stomach and small intestine. In order for normal aerobic metabolism to continue, oxygen extraction must have increased. The addition of nitroprusside to hypoxemia did not significantly change this decrease in oxygen delivery to the stomach. It was not possible, in these studies, to determine whether the stomach was near its maximal ability to extract oxygen during hypoxemia.

Total renal blood flow in neonatal lambs has been reported to decrease $25-35 \%$ during hypoxemia (23). Although a decrease of a similar magnitude was possible but not significant in the present study, renal oxygen delivery fell significantly. The addition of nitroprusside resulted in a large additional decrease in renal oxygen delivery. Data are not available to assess the ability of the kidney in the newborn to maintain its oxygen consumption during periods of decreased oxygen delivery. However, in a manner similar to the gastrointestinal tract, the kidney may not be able to compensate for the large decrease in the delivery of oxygen found during nitroprusside infusion. Similarly, hypoxemia increased blood flow to the neonatal carcass so that oxygen delivery was maintained. Nitroprusside infusion caused a decrease in carcass oxygen delivery by decreasing carcass blood flow. Maintenance of normal metabolism again requires that either oxygen extraction increase or oxygen consumption fall.

To summarize, the infusion of a systemic vasodilator, nitroprusside, during a period of arterial hypoxemia produces a number of alterations in blood flow and oxygen delivery. Both the redistribution of cardiac output and the local tissue regulation of oxygen extraction act, in concert, to maximize organ oxygen availability during hypoxemia. Nitroprusside interferes with this physiologic adjustment by decreasing oxygen delivery to the brain. Those organs which increase oxygen extraction as their primary means of maintaining oxygen consumption such as the gastrointestinal tract, kidney, and carcass, may also be affected if the decrease in oxygen delivery exceeds their ability to extract sufficient oxygen.

Nitroprusside, when given intravenously, possibly combines with sulfhydryl groups in red cells and other tissues to release cyanide. Hepatic "rhodanase" then converts circulating cyanide to thiocyanate (21). Nitroprusside is usually given in higher doses and for a longer time than in the present experiment in order to cause accumulations of cyanide and thiocyanate. We were not able to detect cyanide or thiocyanate during our infusion of nitroprusside. Thus, the effects found on blood flow and oxygen delivery are due to nitroprusside and not the accumulation of toxic metabolites.

The relationship of the present experiment to the use of nitroprusside in the human neonate, although speculative, deserves comment. The use of nitroprusside has been proposed for circumstances such as persistent fetal circulation and respiratory distress syndrome in which hypoxemia is a prominent problem. We would expect, based on animal evidence, that the human neonate responds to hypoxemia by changing blood flow distribution so that oxygen delivery to heart and brain is maintained. Unless nitroprusside, when given to the hypoxemic neonate, causes an increase in arterial oxygen content, we expect that circulatory changes similar to those found in the present experiment could result in decreased cerebral oxygen delivery. Such a decrease in oxygen delivery in the susceptible newborn might increase the risk of hypoxic damage. Therefore, nitroprusside, and possibly other vasodilators as well (22), should be used with caution in the hypoxemic newborn infant.

\section{REFERENCES}

1. Abbott TR, Rees GJ, Dickinson D, Reynolds G, Lord D 1978 Sodium nitroprusside in idiopathic respiratory distress syndrome. Br Med J 1:1113

2. Aldridge WN 1945 The estimation of micro quantities of cyanide and thiocyanate. Analyst 70:474

3. Baer RW, Verrier ED, Vlahakes GJ, Payne DB, Hoffman JIE 1980 Validation of eight sequential myocardial blood flow determinations with radioactive microspheres using least-squares analysis. Circulation Part Il:62:III-65 (abstr)

4. Beverley DW, Hughes CA, Davies DP, Harran MJ, Ducker DA 1979 Early reduction by sodium nitroprusside (SNP) in asphyxiated infants with hypertension and heart failure. Pediatr Res 15:653 (abstr) use of sodium nitroprusside in respiratory distress syndrome. Arch Dis Child $54: 403$

5. Buckberg GD, Luck JC, Payne DB, Hoffman JIE, Archie JP, Fixler DE 197I Some sources of error in measuring regional blood flow with radioactive microspheres. J Appl Physiol 31:598

6. Cabal LA, Barrenechea I, Fumagalli E, Siassi B, Hodgman JE 1981 Afterload

7. Dantzker DR, Bower JS 1981 Pulmonary vascular tone improves $\dot{V}_{\mathbf{A}} / \dot{Q}$ matching in obliterative pulmonary hypertension. J Appl Physiol 51:607

8. Drummond WH, Gregory GA, Heymann MA, Phibbs RA 1981 The independent effects of hyperventilation, tolazoline, and dopamine on infants with persistent pulmonary hypertension. J Pediatr 98:603

9. Edelstone DI, Lattanzi DR, Paulone ME, Holzman IR 1983 Neonatal intestinal oxygen consumption during arterial hypoxemia. Am J Physiol 244:G278

10. Feldstein M, Klendshoj NC 1954 The determination of cyanide in biological fluids by microdiffusion analysis. J Lab Clin Med 44:166

11. Heymann MA, Payne DB, Hoffman JIE, Rudolph AM 1977 Blood flow measurements with radionuclide-labeled particles. Prog Cardiovasc Dis 20:55

12. Jones MD Jr, Traystman RJ, Simmons MA, Molteni RA 1981 Effects of changes in arterial $\mathrm{O}_{2}$ content in cerebral blood flow in the lamb. Am J Physiol 240:H209

13. Koivikko A 1969 Cardiovascular response of the neonatal lamb to hypoxia, hypercapnia, and metabolic acidosis. Acta Paediatr Scand Suppl 191:1

14. Levin DL, Heymann MA, Kittermann JA, Gregory GA, Phibbs RH, Rudolph AM 1976 Persistent pulmonary hypertension of the newborn infant. J Pediatr $89: 626$

15. Makowski EL, Meschia G, Droegemueller W, Battaglia FC 1968 Measurement of umbilical blood flow in the sheep placenta and fetus in utero. Circ Res 23:623

16. Palmer RF, Lasseter KC 1975 Drug therapy. Sodium nitroprusside. N Engl J Med 292:294

17. Rossen RM, Alderman EL, Harrison DC 1976 Circulatory response to vasodilator therapy in congestive cardiomyopathy. Br Heart J 38:695

18. Rudolph AM, Heymann MA 1967 The circulation of the fetus in utero. Methods for studying distribution of blood flow, cardiac output, and organ blood flow. Circ Res 21:163

19. Sidi D, Kuipers JRG, Teitel D, Heymann MA, Rudolph AM 1983 Developmental changes in oxygenation and circulatory responses to hypoxemia in lambs. Am J Physiol 245:H674

20. Thibeault DW, Gregory GA (eds) 1979 Neonatal Pulmonary Care. AddisonWesley, Menlo Park, CA, p 125

21. Tinker JH, Michenfelder JD 1976 Sodium nitroprusside: pharmacology, toxicology, and therapeutics. Anesthesiology 45:340

22. Tripp ME, Drummond WH, Heymann MA, Rudolph AM 1980 Hemodynamic effects of pulmonary arterial infusion of vasodilators in newborn lambs. Pediatr Res 14:1311

23. Weismann DN 1982 Tissue oxygen delivery in lambs: effect of postnatal age and acute hypoxemia. Biol Neonate 42:15

24. Zar JH 1974 Biostatistical Analysis. Prentice Hall, Englewood Cliffs, NJ 